Article

\title{
Enhanced Removal of Soluble and Insoluble Dyes over Hierarchical Zeolites: Effect of Synthesis Condition
}

\author{
Ani Iryani ${ }^{1}\left(\mathbb{D}\right.$, Ahmad Masudi $^{2}$, Ade I. Rozafia ${ }^{2}$, Djoko Hartanto ${ }^{2, *} \mathbb{C}$, Mardi Santoso ${ }^{2}$, \\ Hadi Nur ${ }^{3}$ and Mohammad S. Azami ${ }^{4}$ (D) \\ 1 Department of Chemistry, Faculty of Mathematics and Natural Sciences, Pakuan University, \\ Bogor 16143, Indonesia; ani_iryani62@unpak.ac.id \\ 2 Department of Chemistry, Faculty of Mathematics and Analytical Data, Institut Teknologi Sepuluh \\ Nopember, Surabaya 60111, Indonesia; masudi.ahmad@graduate.utm.my (A.M.); \\ adeirma20@gmail.com (A.I.R.); tsv09@chem.its.ac.id (M.S.) \\ 3 Centre for Sustainable Nanomaterials, Ibnu Sina Institute for Scientific and Industrial Research, \\ Universiti Teknologi Malaysia, Johor Bahru 81310, Malaysia; hadi@kimia.fs.utm.my \\ 4 Faculty of Science, Universiti Teknologi Malaysia, Universiti Teknologi Malaysia, \\ Johor Bahru 81310, Malaysia; saifulddinazami@gmail.com \\ * Correspondence: djokohar@its.ac.id
}

Received: 26 August 2020; Accepted: 16 September 2020; Published: 20 September 2020

\begin{abstract}
A hierarchical zeolite ZSM-5 with micro and meso-pore was prepared by optimising the most affecting parameter in sequence of desilication and dealumination. The physicochemical properties of zeolite were characterised with XRD, nitrogen adsorption-desorption, FTIR and SEM. The potential of this zeolite for decolorisation of CR, RY, MB, RhB, DB-1 and DB- 14 was evaluated with adsorption isotherm, thermodynamics, kinetics, and influencing parameter for adsorption. The unique modification of ZSM-5 resulted in lower crystallinity, easier porosity control, rich terminal silanol and unbridged silanol groups which assisted in higher adsorption capacity. The adsorption capacity of the optimum ZSM- 5 was 323, 435, 589, 625, 61 and $244 \mathrm{mg} / \mathrm{g}$ for CR, RY, MB, RhB, DB-1 and DB-14, respectively. The dye adsorption progressed through pseudo-first-order kinetic and close to the Langmuir model. The adsorption mechanism is proposed mainly through interaction between deprotonated silanol site and the electron-rich dye site.
\end{abstract}

Keywords: hierarchical zeolite; soluble dye; insoluble dye; adsorption; silanol; surface area

\section{Introduction}

Increasing population and life standards of modern people in the past decade demand for establishing various industries such as leather, plastics, cosmetics, paper, rubber, printing inks, paints, and etc. These industries were developed in many countries, which sometimes discharge their pollutants to the environment. One of the serious hazardous contaminants is the synthetic dyes that generally consist of conjugated organic molecules [1]. Although the amount of dye discharge was not clearly reported in any industry, but it must be large considering the reported environmental issue. The dyes discharge worldwide was predicted at around 700,000 tonnes per year which is $70 \%$ of the dye production [2]. These compounds usually absorb sunlight radiation and block the penetration to water, then limiting the growth of aquatic life. Additionally, many of synthetic dyes are carcinogens in certain concentration [3].

Generally, based on its solubility, dyes could be classified as soluble and insoluble. The soluble dye consists of reactive, mordant, acid, alkaline while the insoluble dyes are azo, sulphur, disperse and 
vat. From these categories, acid, alkaline reactive and disperse are the most common dye industry worldwide [4]. In brief, the removal of synthetic dyes received enormous interest in recent years with escalating concern to environmental protection.

There are many techniques for dye removal including biological [5], coagulation [6], membrane separation [7], flocculation [8] and adsorption [9]. Adsorption is considered as the most feasible method because of its ability to remove various pollutants at affordable cost with excellent stability and high surface area [10]. The common adsorbents are carbon, clays, polymeric substances and zeolite. Zeolite is a crystalline alumino-silica having microporous structure with exchangeable cations. However, the small pore zeolite restricted the diffusion of reagents, thus limiting its efficiency [11].

Zeolite could be categorised as large, medium and small pore. This classification distinguishes each other with the pore sizes in the range $0.60-0.85,0.46-0.6$ and $0.30-0.40 \mathrm{~nm}$ for large, medium and small zeolite, respectively [12]. ZSM-5 is among the most widely produced zeolitic material which is prominent in oil catalytic cracking. The synthesis protocol for production of ZSM-5 still attracted many researchers with elevating chemical needs from oil. Our group has successfully produced ZSM-5 from abundant feedstock such as kaolin [13] and rice husk [14]. The zeolite that was produced from metakaolin has potential to be used as an adsorbent as reported in literature [15].

The main limitation of the widely used ZSM-5 was related to its microporous nature. One method to improve reagent diffusion could be achieved by producing zeolite with various porosity which is known as hierarchical [16]. To the best of our knowledge, only limited studies investigating the potency of hierarchical zeolites as adsorbent for removal of dyes have been published. By using hierarchical zeolites, dyes molecules diffusion could be easier and with more accessible surface area that supposedly increases the removal efficiency. There are two general approaches to produce hierarchical zeolites namely bottom-up [17] and top-down [18]. Bottom-up have several limitations such as poor mechanical strength, complicated to control secondary porosity, time consuming and limited template [19]. Thus, top-down method seems promising, especially for scale-up production and hindered previous problem.

Although zeolite production with top-down was reported in several literatures [20-22], but still a few studies included sequence route of desilication-dealumination with details on the interaction between adsorbent and discharged dye. This study aims to investigate the optimum condition to produce hierarchical ZSM-5 with initial breakthrough of textile effluents in industry, especially in handling insoluble dyes.

\section{Results and Discussions}

\subsection{Crystallinity and Phase Purity}

In this study, we optimised first the concentration of $\mathrm{NaOH}$ and $\mathrm{CH}_{3} \mathrm{COOH}$ to produce the hierarchical ZSM-5 from commercial ZSM-5. The optimum concentration was estimated by identifying the XRD intensity of the samples which is proved as a simple method to distinguish zeolite crystallinity [23]. Figure S1 exhibits the crystallinity of ZSM-5 based on Equation (2) as follows,

$$
\% \text { Crystallinity }=\frac{I_{\text {sample }}}{I_{\text {ref }}} \times 100 \%
$$

Figure 1 displays XRD diffractogram of the adsorbents that consist of (a) ZSM- $5_{\text {comm, (b) ZSM- }}$ deAl, (c) ZSM-5 deSil and (d) ZSM-5 deSil-deAl. The peaks appeared at 20 7.96, 8.83, 23.18, 23.99 and 24.45. This pattern matched with pure MFI type zeolite without any other amorphous or crystalline impurities [24,25]. The pattern exhibited no significant changes after the treatment which shows that zeolite still maintained the MFI structure. However, the crystallinity decreased as follow: ZSM- $5 \mathrm{deAl}-\mathrm{deSil}$ $<$ ZSM-5 deAl $<$ ZSM-5 deSil $<$ ZSM-5 comm. The decreasing crystallinity could be correlated with silica and alumina removal from zeolite framework. This trend is similar with previous studies where peak broadening and decreasing intensities are consequences of mesopore generation that led to the creation of hydroxyl cavities and scission of Al-O bonds [26,27]. This study also verified that the 
treatment in $\mathrm{NaOH}$ has lower impact to crystallinity compared to $\mathrm{CH}_{3} \mathrm{COOH}$ signifying its effective ionic removal from the zeolitic framework. Lastly, the lowest intensity in ZSM- $5_{\text {deAl-deSi }}$ may be caused by the removal of both silica and alumina within the framework.

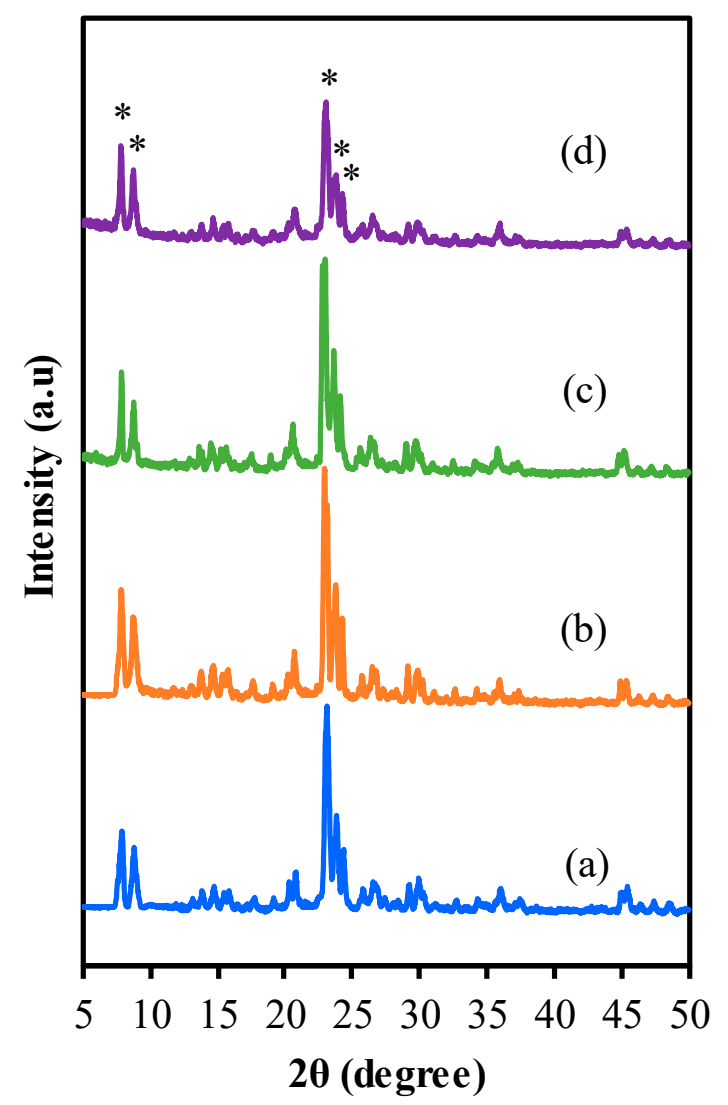

Figure 1. XRD pattern of (a) ZSM- $5_{\text {comm, }}$ (b) ZSM- $5_{\text {deAl }}$, (c) ZSM- $5_{\text {deSil }}$ (d) ZSM- $5_{\text {deSil-deAl }}\left(^{*}\right)$ refer to peaks at $7.96,8.83,23.18,23.99$ and 24.45 .

\subsection{Textural Properties}

Figure 2a shows isotherm of nitrogen adsorption-desorption for (a) ZSM- $5_{\text {comm }}$, (b) ZSM- $5_{\text {deAl }}$, (c) ZSM- $5_{\text {deSil }}$, and (d) ZSM-5 deSil-deAl. The ZSM- $5_{\text {comm }}$ follows type I isotherm with loop $\mathrm{H}_{3}$ which may be assigned to microporous structure. Then, after the treatment, hysteresis loop became more intense at $P / P o$ higher than 0.5 with vertical fracture at $P / P_{0}<0.2$ and $P / P o>0.9$ indicating the formation of mesoporous structure and micropore respectively. This also signifies that larger pore formation could be originated from inter-crystalline pore structure [26]. 

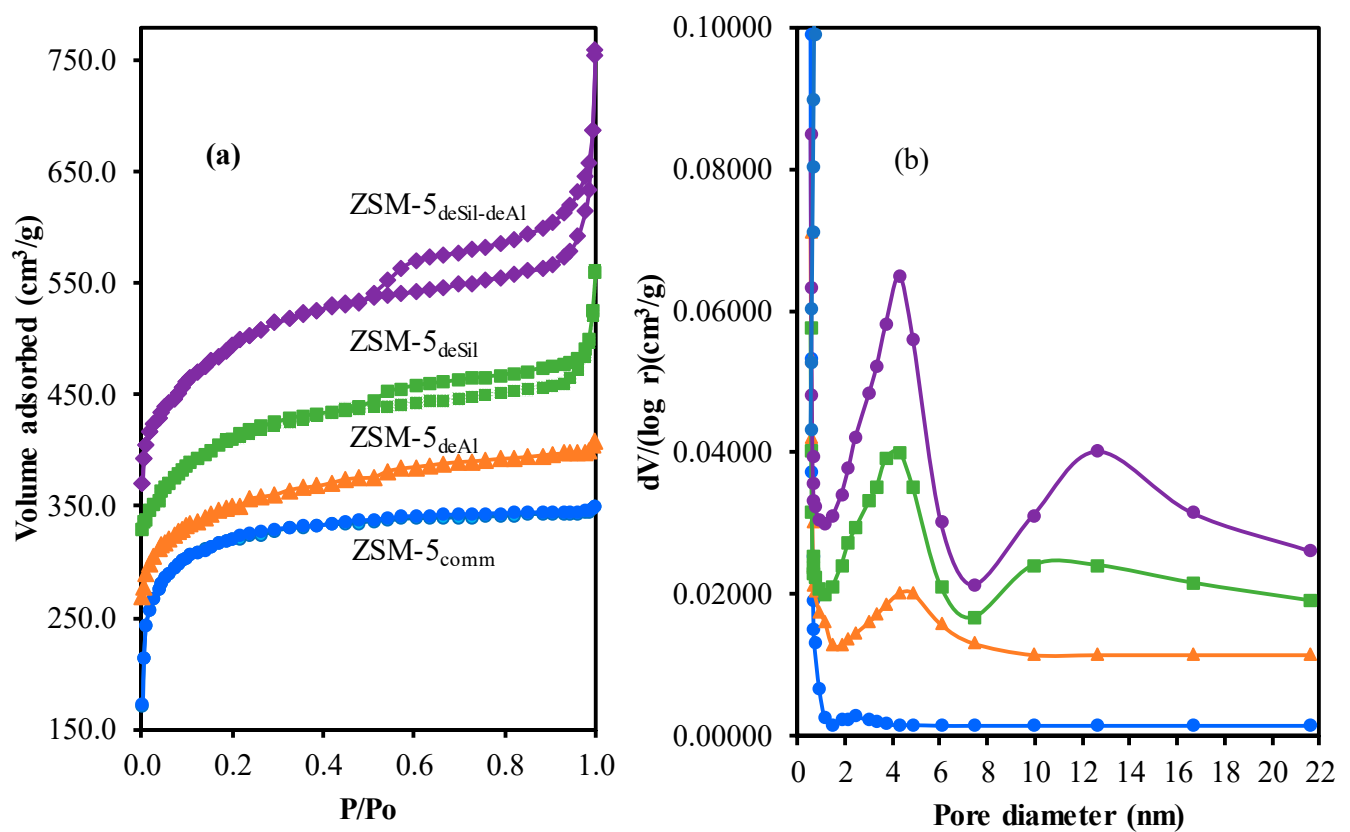

Figure 2. (a) $\mathrm{N}_{2}$ isotherm adsorption desorption of the adsorbent, (b) pore size distributions of adsorbents.

Table 1 shows surface area and pore volume of the adsorbents. A decreasing trend of $S_{\text {ext }}$ is monitored after the treatment with an increase of $S_{\mathrm{BET}}$ attributing to the creation of new pore or formation of larger pore. The $S_{\mathrm{BET}}$ of ZSM- $5_{\mathrm{deAl}}$ is smaller than ZSM-5 $5_{\mathrm{comm}}$ which may be due to micropore blockage from alumina fragment in zeolite framework. Pore size distribution of the adsorbents is displayed in Figure $2 \mathrm{~b}$. The surface area of ZSM- $5_{\text {comm }}$ is mainly due to the micropore structure with pore size of $0.56 \mathrm{~nm}$. Then, the amount of micropore decreased after the treatment as the dissolving alumina and silica may be crystallized as terminal parts of the crystal structure. Meanwhile, the amount of mesopore in the range of $4-5 \mathrm{~nm}$ increased and reached the optimum for ZSM- $5_{\mathrm{deSil}}$-deAl indicating the significance of production route as reported by Akhtar et al. [28].

Table 1. Surface area and pore volume of the adsorbents.

\begin{tabular}{|c|c|c|c|c|c|c|c|}
\hline \multirow{2}{*}{ Sample } & \multicolumn{3}{|c|}{ Surface Area $\left(\mathrm{m}^{2} / \mathrm{g}\right)$} & \multicolumn{3}{|c|}{ Pore Volume $\left(\mathrm{cm}^{3} / \mathrm{g}\right)$} & \multirow{2}{*}{$\begin{array}{c}\text { pHpzc } \\
\text { (S3) }\end{array}$} \\
\hline & $S_{\text {BET }}$ & $S_{\text {micro }}$ & $S_{\text {ext }}$ & $V_{\text {tot }}$ & $V_{\text {micro }}$ & $V_{\text {meso }}$ & \\
\hline ZSM-5 comm $_{\text {. }}$ & 353 & 242 & 111 & 0.201 & 0.138 & 0.012 & 7.62 \\
\hline ZSM- $5_{\mathrm{deAl}}$ & 348 & 229 & 66 & 0.181 & 0.124 & 0.065 & 7.93 \\
\hline ZSM-5 deSil & 366 & 213 & 52 & 0.188 & 0.111 & 0.074 & 7.38 \\
\hline ZSM-5 deSil-deAl & 428 & 271 & 97 & 0.238 & 0.131 & 0.098 & 7.55 \\
\hline
\end{tabular}

An interesting phenomenon is observed during the treatment with alkaline solution. The alkaline treatment requires high concentration of $\mathrm{NaOH}(0.25 \mathrm{M})$ compared to $0.01 \mathrm{M}$ of $\mathrm{CH}_{3} \mathrm{COOH}$ in acidic treatment. Low concentration of $\mathrm{NaOH}(0.01 \mathrm{M})$ could not form any mesopore structure with the ability to increase the pore size from 0.56 to $1 \mathrm{~nm}$ (data not shown here). Thus, lower concentration of $\mathrm{NaOH}$ is not effective to produce hierarchical ZSM-5. This phenomenon could be explained as follows. Alkaline treatment has higher tendency to react with $\mathrm{Si}^{4+}$ because of its stronger acidity. Meanwhile, some of $\mathrm{Al}^{3+}$ reacted with silanol groups and blocked some of the micropore structure. The remaining $\mathrm{Al}^{3+}$ lead to agglomeration and formed bigger size of mesopore structure. On the contrary, low concentration of $\mathrm{CH}_{3} \mathrm{COOH}$ is preferable for acid treatment as the zeolite framework 
may collapse at high concentration. For the combination of alkali and acid treatment, some of the $\mathrm{Al}^{3+}$ and $\mathrm{Si}^{4+}$ were removed from ZSM-5 framework and resulted in the generation of more mesoporous structure. Then, to further verify the content of $\mathrm{Al}^{3+}$ and $\mathrm{Si}^{4+}$, the $\mathrm{ZSM}-5$ after each treatment was washed with water and acetic acid glacial, and the result is listed in Table 2. It is clearly seen that some of the $\mathrm{Al}^{3+}$ are trapped in ZSM-5 framework without combination of alkali and acid treatment. This result also strengthened that removal of $\mathrm{Si}^{4+}$ and $\mathrm{Al}^{3+}$ and contributed to new pore formation as presented in Figure 3.

Table 2. The $\mathrm{Al}^{3+}$ and $\mathrm{Si}^{4+}$ contents after treatment and washing.

\begin{tabular}{ccccccc}
\hline \multirow{2}{*}{ Sample } & $\begin{array}{c}\text { Filtrate after Treatment } \\
(\mathbf{m m o l} / \mathbf{L})\end{array}$ & $\begin{array}{c}\text { Washing with Water } \\
(\mathbf{m m o l} / \mathbf{g})\end{array}$ & \multicolumn{2}{c}{$\begin{array}{c}\text { Washing with Acetic } \\
\text { Acid (mmol/g) }\end{array}$} \\
\cline { 2 - 7 } & $\mathbf{S i}$ & $\mathbf{A l}$ & $\mathbf{S i}$ & $\mathbf{A l}$ & $\mathbf{S i}$ & $\mathbf{A l}$ \\
\hline ZSM-5 $\mathrm{comm}$ & - & - & 0 & 0 & 0.01 & 0.01 \\
\hline ZSM-5 & 90 & 0.03 & 0 & 0.02 & 3 & 25 \\
\hline ZSM-Al & 32 & 25 & 0 & 0 & 4 & 9 \\
\hline ZSM-5 deSil & 120 & 45 & 0 & 0 & 3 & 5 \\
\hline
\end{tabular}<smiles>CC(C)(C)O[Si](C)(C)O[Si](C)(C)O[Si](C)(C)O[Si](C)(C)O</smiles><smiles>[3H][13CH3]</smiles>

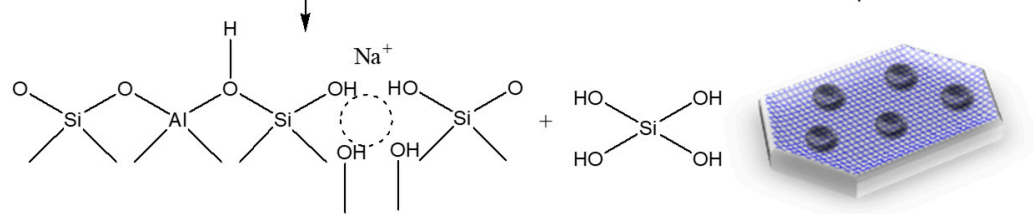

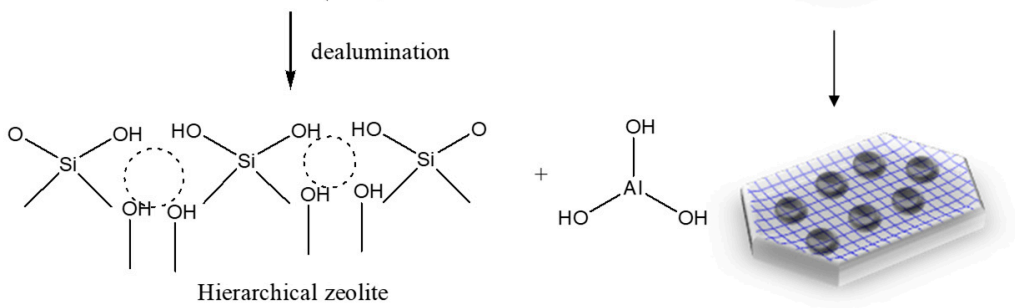

Figure 3. Transformation from microporous to hierarchical ZSM-5 (dotted circle refers to new porosity formation).

\subsection{Vibrational Spectroscopy}

The FTIR spectra of the adsorbents is depicted in Figure 4a. The peaks of commercial ZSM-5 and hierarchical ZSM-5 appeared at 455, 543, 790, 1087 and $1218 \mathrm{~cm}^{-1}$ [13]. The band at $455 \mathrm{~cm}^{-1}$ correspond to internal framework of T-O-T, where T is both $\mathrm{Al}$ and Si. Meanwhile, the peak at $543 \mathrm{~cm}^{-1}$ is assigned to pentasil ring vibration of MFI zeolite topology of which the high intensity could be correlated to its high crystallinity. Then, the peak at $1218 \mathrm{~cm}^{-1}$ contributed to the external asymmetric stretching vibration of five-membered rings [29]. Finally, the peak at $1087 \mathrm{~cm}^{-1}$ is characteristic of silanol groups which could be deconvoluted to three peaks namely 1078, 1087 and $1090 \mathrm{~cm}^{-1}$ as presented in S2. These peaks originated from asymmetric stretching vibration of $\mathrm{Si}-\mathrm{O}-\mathrm{Si}, \mathrm{Si}-\mathrm{OH}$ and un-bridge Si-O [30]. The Gaussian peak area for terminal Si-OH and un-bridge Si-O as presented in Figure $4 \mathrm{~b}$ increased and reached a maximum value in ZSM-5 deSil-deAl confirming the destruction of some alumina-silica framework and aligned with XRD and nitrogen adsorption-desorption studies. 

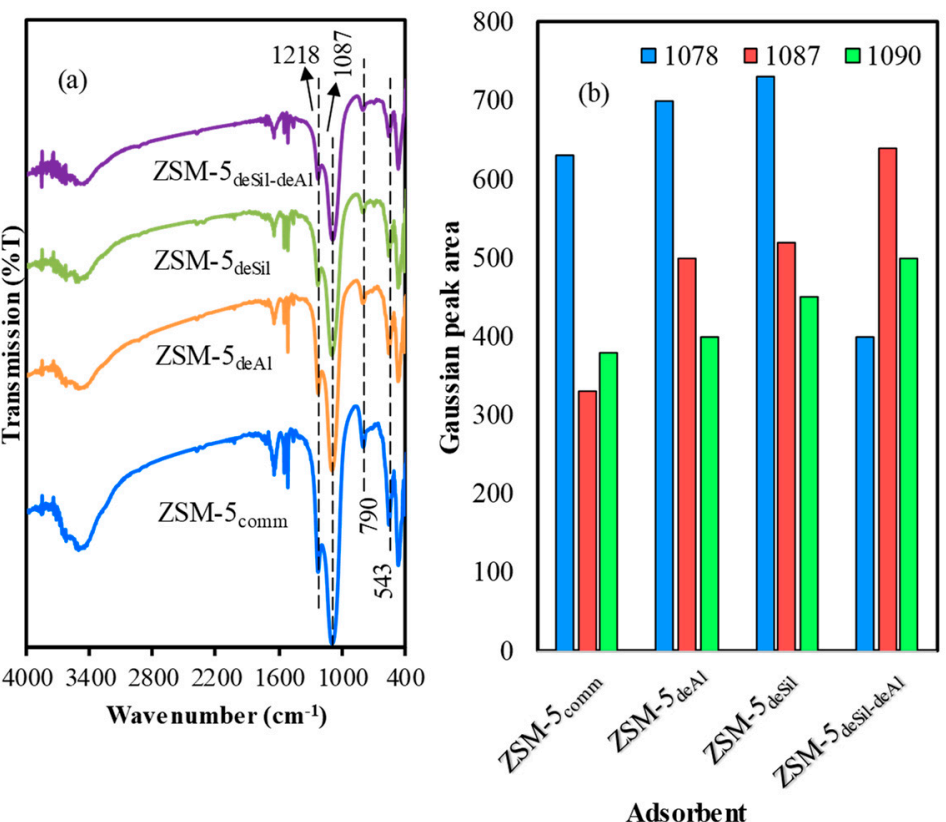

Figure 4. (a) FTIR results for all adsorbents (b) Gaussian peak area of $1087 \mathrm{~cm}^{-1}$.

\subsection{Adsorbent Morphologies}

The morphological structures of the adsorbents are presented in Figure 5. According to SEM, it can be inferred that the treatment did not bring any significant changes to the crystal size. The crystal size does not differ distinctly as also confirmed with XRD. However, the surface of ZSM- 5 changes from fine to coarse after the treatment. This change may be due to formation of new pores which consisted of meso and macropore structure after the treatment. This result is in line with the XRD result and nitrogen adsorption-desorption. The silicium and alumina ion within ZSM-5 framework may dissolve, thus decreasing the surface of inter-crystalline structure and forming new pores with various sizes.
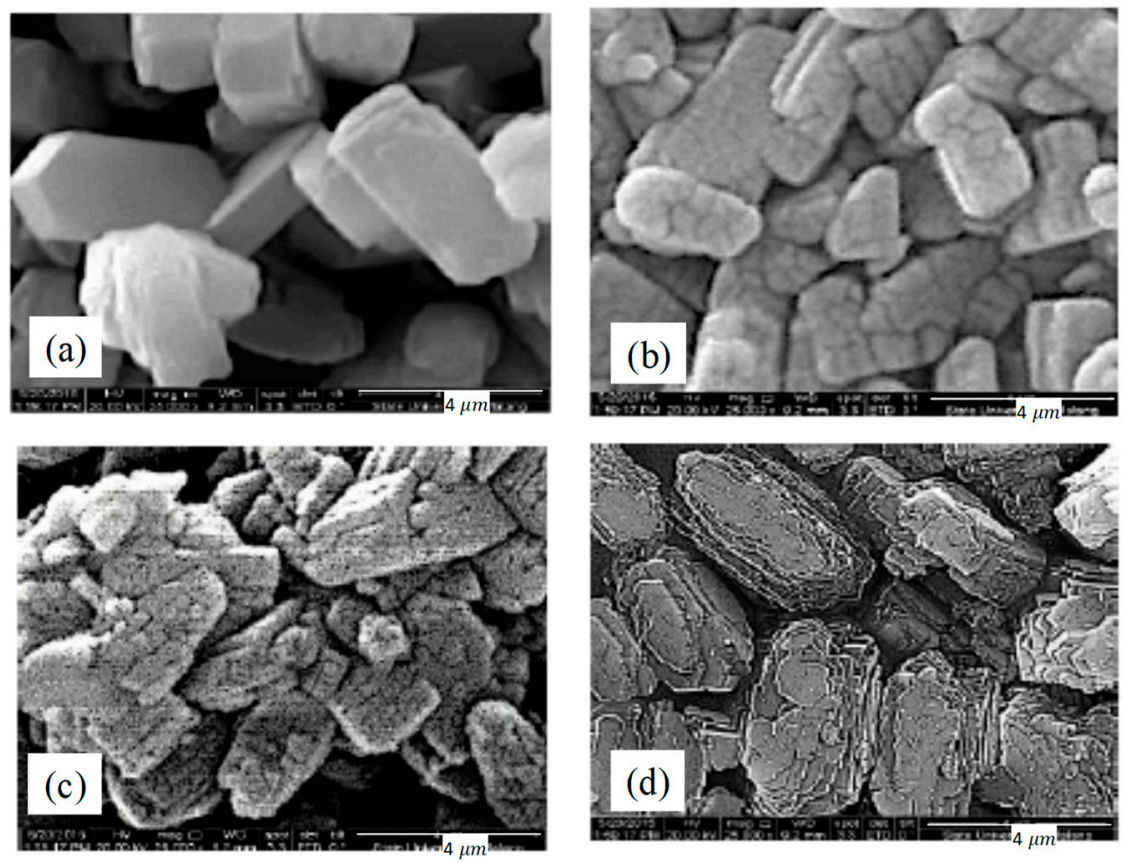

Figure 5. Morphologies of the adsorbents

(a) ZSM-5

(b) ZSM- $5_{\mathrm{deAl}}$

(c) ZSM- $5_{\text {deSil }}$

(d) ZSM-5 deSildeAl. 


\subsection{Adsorption Study}

Adsorption isotherm study is crucial in designing efficient adsorbent for certain adsorbate. In this study, the adsorption capacity was verified by fitting experimental data with Langmuir model. In Langmuir model, it was hypothesised that the dye adsorption occur in monolayer on the surface of adsorbent. This model also proposes that adsorbate molecules have no interaction with each other. The Langmuir model is expressed in Equation (3) [31].

$$
\frac{C_{e}}{Q_{e}}=\frac{C_{e}}{Q_{m}}+\frac{1}{Q_{m}} k_{L}
$$

where $C_{e}$ and $Q_{e}$ are the dye concentration in solution at equilibrium and the amount of adsorbed dye at equilibrium, respectively. Meanwhile, $k_{L}$ denotes the Langmuir constant and $Q_{m}$ as maximum adsorption capacity. After plotting $C_{e} / Q_{e}$ vs. $C_{e}, k_{L}$ and $C_{e} / Q_{e}$ could be obtained from intercept and slope. From Table 3, it can be clearly observed that $R^{2}$ is larger than 0.99 indicating the appropriateness of the model. Hence, we can assume that dye adsorption occur as a monolayer on the surface of the adsorbent.

Table 3. Dyes isotherm adsorption model.

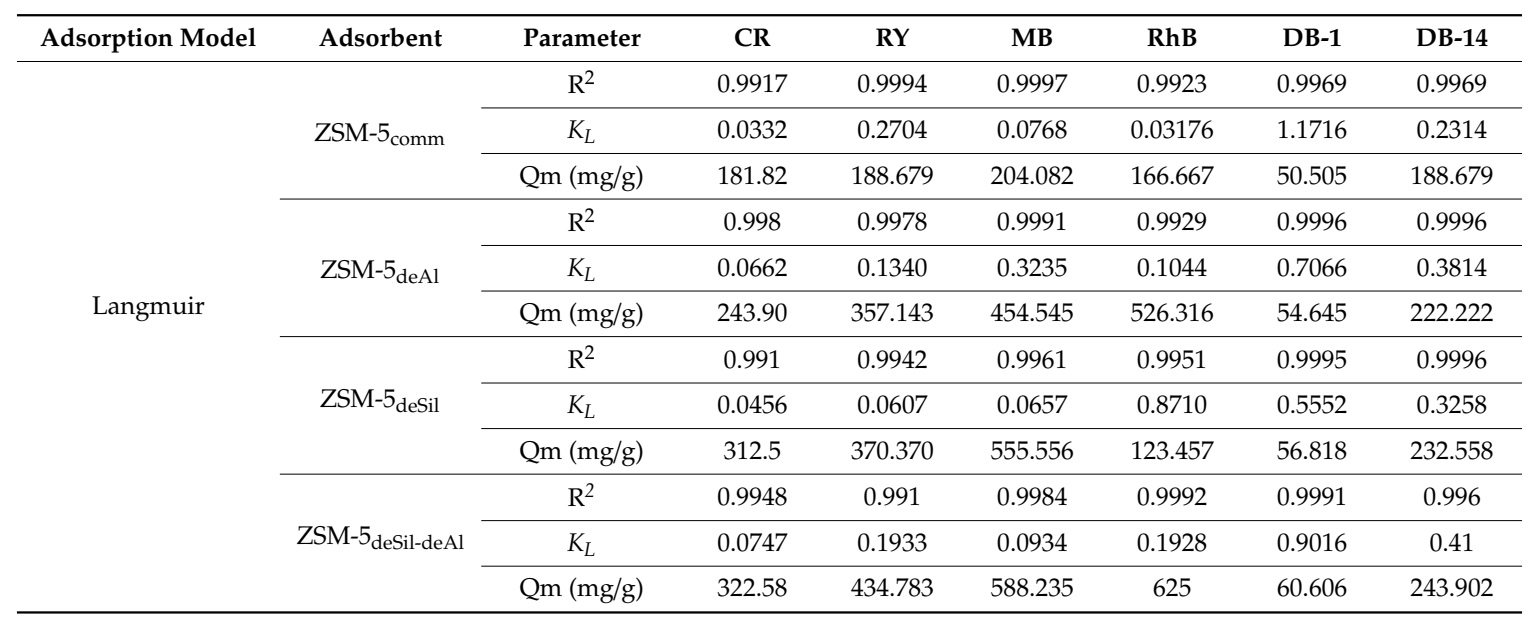

\subsubsection{Adsorption Thermodynamics}

The elaboration of the adsorption thermodynamics is crucial in understanding the energetic changes during certain processes. Some thermodynamic parameters such as Gibbs free energy $(\Delta G)$, enthalpy $(\Delta H)$ and entropy $(\Delta S)$ were calculated using Equations (5) and (6). Three different temperatures namely 303,313 and $323 \mathrm{~K}$ were utilised to calculate the contributing thermodynamic parameters [32].

$$
\begin{gathered}
\Delta G=-R T \ln K_{L} \\
\ln \left(K_{L}\right)=\frac{\Delta S}{R}-\frac{\Delta H}{R T}
\end{gathered}
$$

where $K_{L}$ as Langmuir equilibrium constant and $\mathrm{R}$ as gas constant $\left(8.314 \times 10^{-3} \mathrm{~kJ} \mathrm{~mol} / \mathrm{K}\right)$. Then, $\Delta S$ and $\Delta H$ were calculated from intercept and slope by plotting $1 / T$ vs. $\ln K_{L}$, respectively.

All of the thermodynamic parameters are presented in Table 4 and Figure 6 . Increasing temperature, increased the equilibrium constant $(\mathrm{K})$ indicating elevating amount of dye over the adsorbent surface. The adsorption process in this study is considered as a spontaneous reaction because of negative value of free Gibbs energy $(\Delta G)$. Then, the positive enthalpy $(\Delta H)$ assigning to endothermic reaction is favourable to high temperature. The $\Delta H$ increased in this order DB- $1<\mathrm{DB}-14<\mathrm{CR}<\mathrm{RY}<\mathrm{MB}<\mathrm{RhB}$ which displays the same order as dye polarity. This trend is similar with Brião et al. where increasing dipole moment between adsorbent and dye resulted in higher adsorption capacity [33]. DB-1 and 
DB-14 are categorised as insoluble dyes, while the remaining are soluble dye. However, the solubility of DB-14 (38 $\mu \mathrm{g} / \mathrm{L})$ is much higher than DB-1 $(19 \mu \mathrm{g} / \mathrm{L})$. The lower the solubility of DB-1, the lower the interaction with the adsorbent. Hence, removal of DB-1 is the lowest compared to other dyes.

Table 4. Thermodynamic parameters of studied dyes.

\begin{tabular}{|c|c|c|c|c|c|c|}
\hline Dye & $T(\mathrm{~K})$ & $K_{L}$ & $\Delta G(\mathrm{~kJ} / \mathrm{mol})$ & $\Delta H(\mathrm{~kJ} / \mathrm{mol})$ & $\Delta S(\mathrm{~kJ} / \mathrm{mol})$ & $R^{2}$ \\
\hline \multirow{3}{*}{ CR } & 303 & 1.108 & -0.259 & \multirow{3}{*}{108.832} & \multirow{3}{*}{0.371} & \multirow{3}{*}{0.9987} \\
\hline & 313 & 1.212 & -0.501 & & & \\
\hline & 323 & 1.333 & -0.773 & & & \\
\hline \multirow{3}{*}{ RY } & 303 & 1.125 & -0.297 & \multirow{3}{*}{169.004} & \multirow{3}{*}{0.571} & \multirow{3}{*}{0.990} \\
\hline & 313 & 1.273 & -0.62 & & & \\
\hline & 323 & 1.500 & -1.089 & & & \\
\hline \multirow{3}{*}{ MB } & 303 & 1.250 & -0.562 & \multirow{3}{*}{187.226} & \multirow{3}{*}{0.644} & \multirow{3}{*}{0.996} \\
\hline & 313 & 1.448 & -0.964 & & & \\
\hline & 323 & 1.719 & -1.454 & & & \\
\hline \multirow{3}{*}{ RhB } & 303 & 1.189 & -0.434 & \multirow{3}{*}{158.227} & \multirow{3}{*}{0.542} & \multirow{3}{*}{0.985} \\
\hline & 313 & 1.326 & -0.734 & & & \\
\hline & 323 & 1.556 & -1.187 & & & \\
\hline \multirow{3}{*}{ DB-1 } & 303 & 1.029 & -0.071 & \multirow{3}{*}{9.023} & \multirow{3}{*}{0.032} & \multirow{3}{*}{0.997} \\
\hline & 313 & 1.038 & -0.096 & & & \\
\hline & 323 & 1.044 & -0.117 & & & \\
\hline \multirow{3}{*}{ DB-14 } & 303 & 1.067 & -0.162 & \multirow{3}{*}{98.177} & \multirow{3}{*}{0.332} & \multirow{3}{*}{0.995} \\
\hline & 313 & 1.175 & -0.420 & & & \\
\hline & 323 & 1.260 & -0.621 & & & \\
\hline
\end{tabular}

\subsubsection{Effect of $\mathrm{pH}$}

$\mathrm{pH}$ is one of the important parameters in adsorption studies that affects the surface interaction between adsorbent and pollutant. The adsorption studies were conducted at various $\mathrm{pH}$ values in the range of 3-10. Figure 7 exhibits increasing adsorption capacity with increasing $\mathrm{pH}$ for $\mathrm{CR}, \mathrm{RY}, \mathrm{MB}$ and $\mathrm{RhB}$. The repulsive force between adsorbent and dyes occur in acidic solution because of the same charge, lowered the interaction between the adsorbent and dyes, thus resulting in low adsorption capacity. Meanwhile, in alkaline solution the ZSM-5 is negatively charged, while the dyes are in positively charge. Hence, it favours electrostatic interaction and facilitates more adsorption [34,35]. In this study, the optimum $\mathrm{pH}$ for $\mathrm{MB}$ was achieved at 7 , while $\mathrm{CR}, \mathrm{RY}$ and $\mathrm{RhB}$ were at $\mathrm{pH} 8$. This result is in line with the result from $\mathrm{pH}$ point of zero charge $\left(\mathrm{pH}_{\mathrm{pzc}}\right)$ as tabulated in Table 1 and listed in $\mathrm{S} 3$. 

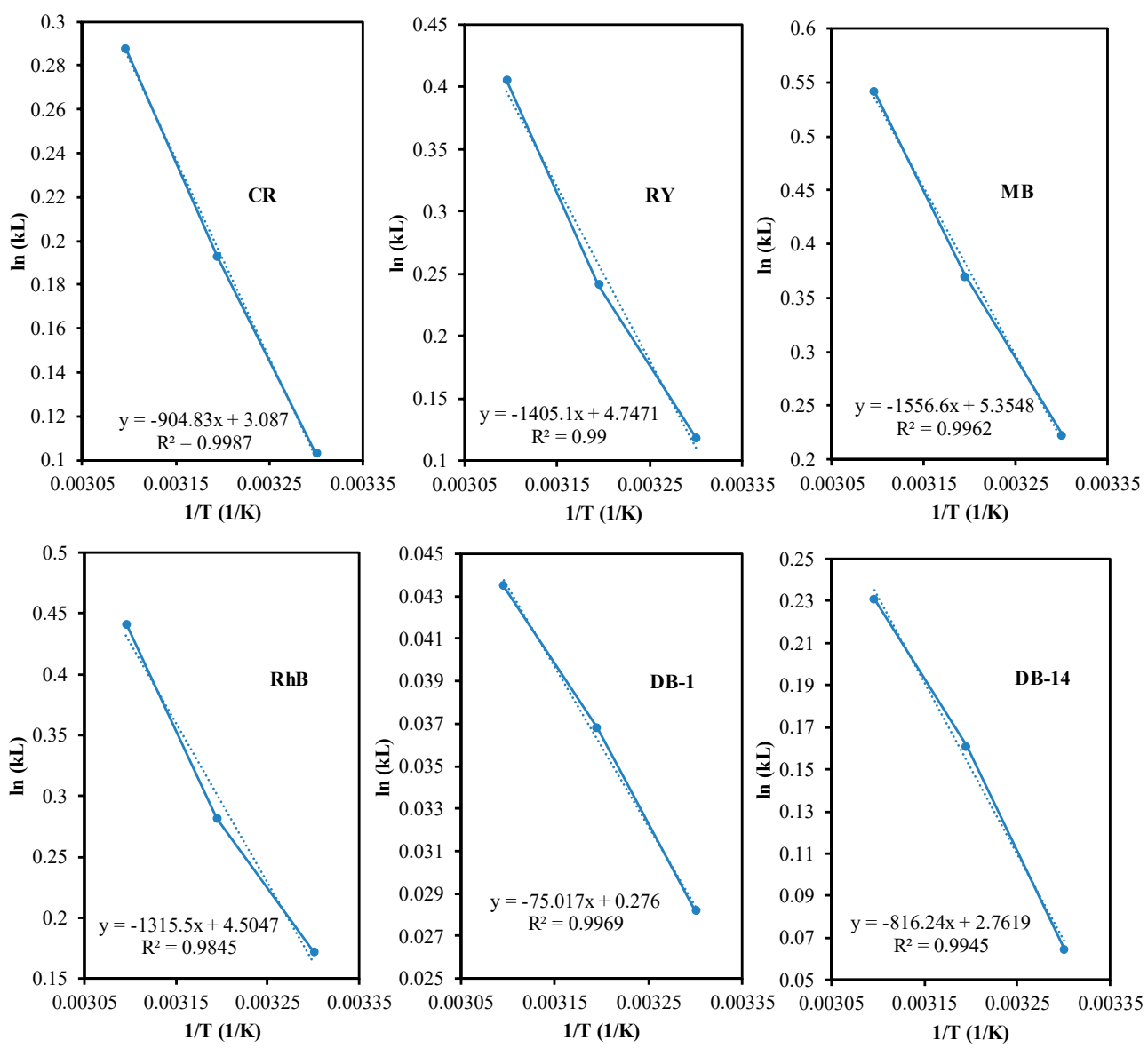

Figure 6. Graph plot of $1 / T$ vs. $\ln k_{L}$.

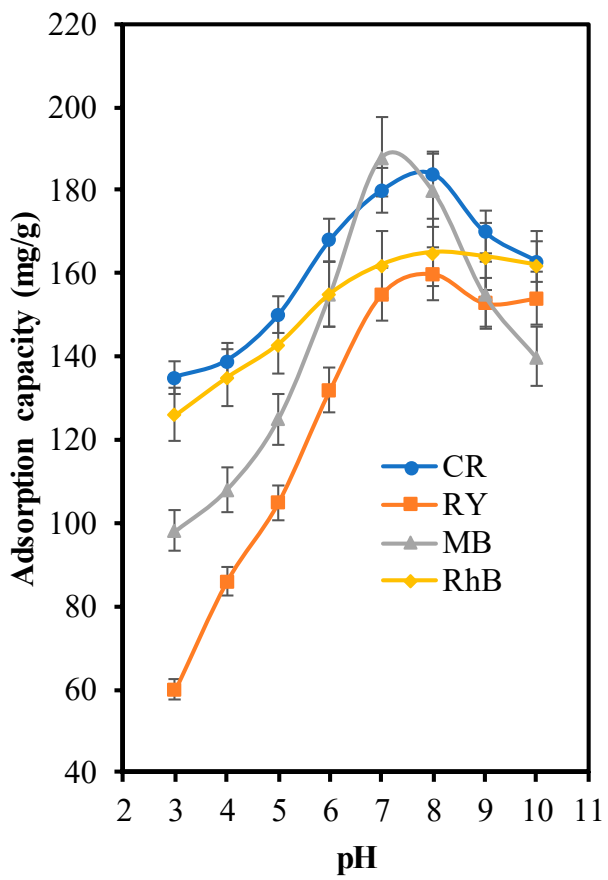

Figure 7. Effect of $\mathrm{pH}$ in dye decolorisation over ZSM- $5_{\text {deSil-deAl. }}$ 


\subsubsection{Effect of Initial Dye Concentration}

Figure 8 displays the dye decolorisation result for the effect of initial dye concentration performance. The initial MB concentrations are 60, 100, 150, 200 and 250 ppm. It is depicted that dye removal decreased with increasing initial concentration. At low concentration, the adsorbent active sites may be sufficient to accommodate almost all the dye molecules [36]. But, the amount of adsorbent active sites in high dye initial concentration may be limited, thus limiting the dye removal activity. This result is similar with Saravanan et al., where dye initial concentration is inversely proportional to dye decolorisation [37].
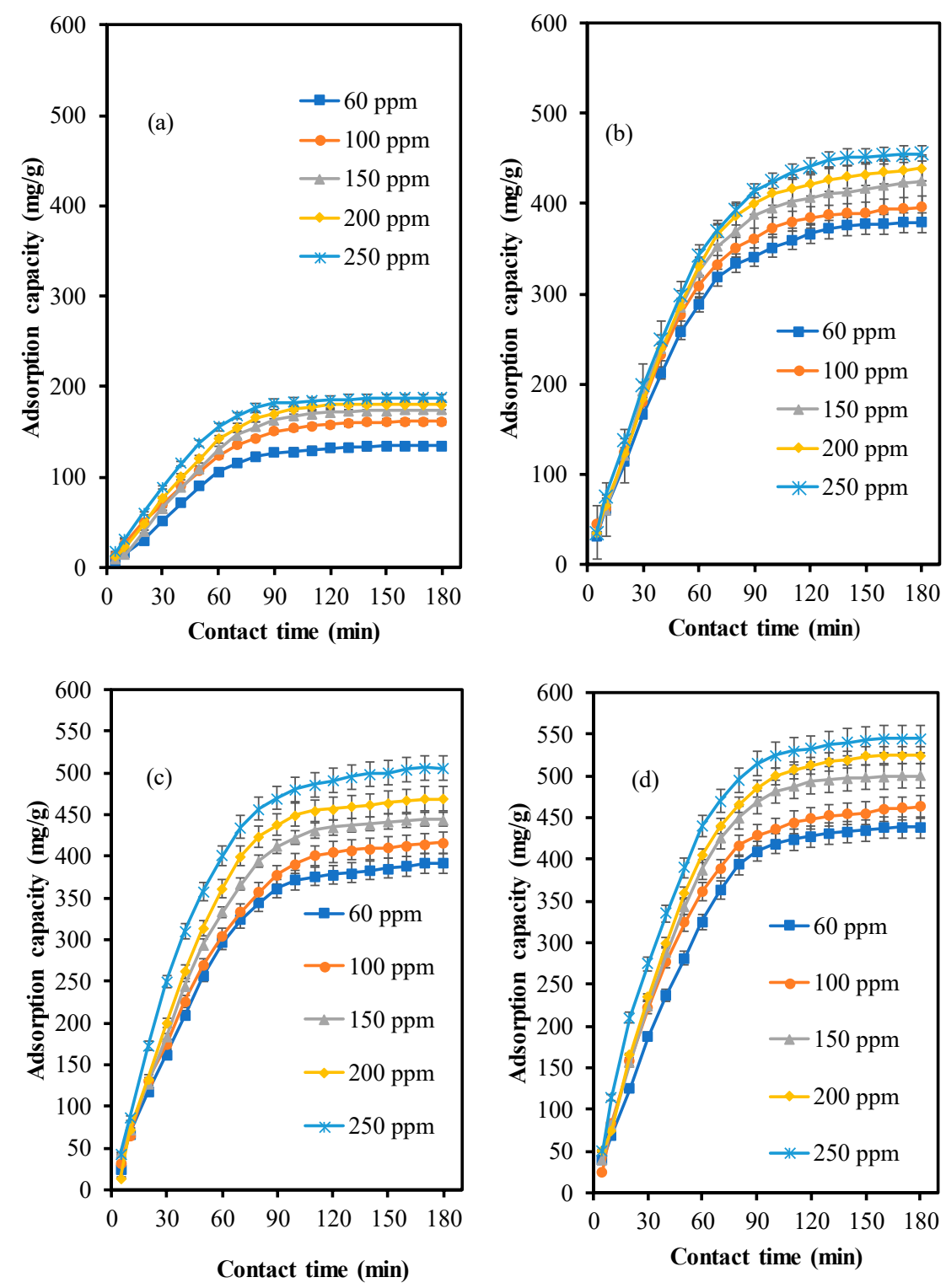

Figure 8. Effect of initial MB concentration over the adsorbents (a) ZSM- $5_{\text {comm }}$ (b) ZSM- $5_{\text {deAl }}$ (c) ZSM-5 deSil (d) ZSM-5 deSil-deAl.

\subsubsection{Effect of Adsorbent Type}

The interaction between dye and adsorbent is another affecting parameter for dye removal and presented in Figure 9. The surface area of ZSM- $5_{\text {comm }}$ is mainly contributed from micropore structure as presented in Table 5, thus limiting the penetration to only small molecules. Then, the surface area decreased in ZSM- $5_{\mathrm{deAl}}$, followed by increasing the amount of macropore. Although the macropore 
structure is beneficial to penetration of larger molecules, but some of internal surface area may be blocked and decrease the dye-adsorbent interaction. The optimum adsorption performance is obtained when the adsorbents consist of micro, meso and macro as reported elsewhere [38,39]. This result is in line with this study where ZSM- $5_{\text {deSil-deAl }}$ showed best performance. In addition to unique pore characteristics, the optimum ZSM- 5 also exhibits highest amount of silanol groups and unbridged $\mathrm{Si}-\mathrm{O}$, as evidenced by FTIR deconvolution, which may also assist in dye removal.

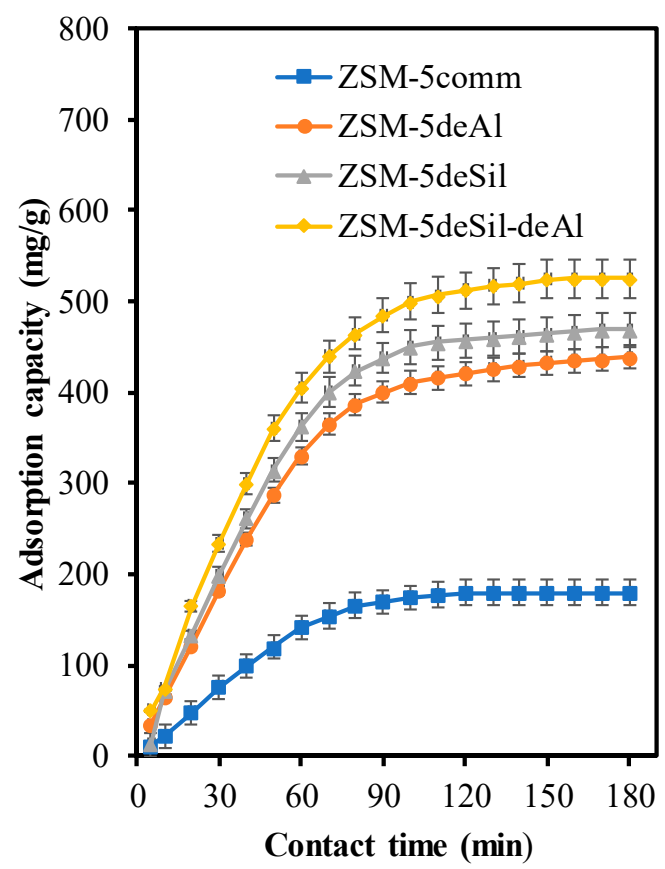

Figure 9. Effect of adsorbent type for MB decolorisation with ZSM-5 deSil-deAl.

Table 5. Characteristics of the studied dyes.

\begin{tabular}{|c|c|c|c|c|}
\hline Dye & Molecular Structure & $\begin{array}{l}\lambda_{\max } \\
(\mathbf{n m})\end{array}$ & $\begin{array}{c}\text { Mw } \\
(\mathrm{g} / \mathrm{mol})\end{array}$ & $\begin{array}{l}\text { Size } \\
\left(\AA^{2}\right)\end{array}$ \\
\hline $\mathrm{CR}$ & & 495 & 696 & $7 \times 25$ \\
\hline RY & & 410 & 593 & $12.7 \times 31.2$ \\
\hline MB & & 663 & 320 & $5.9 \times 13.8$ \\
\hline
\end{tabular}


Table 5. Cont.

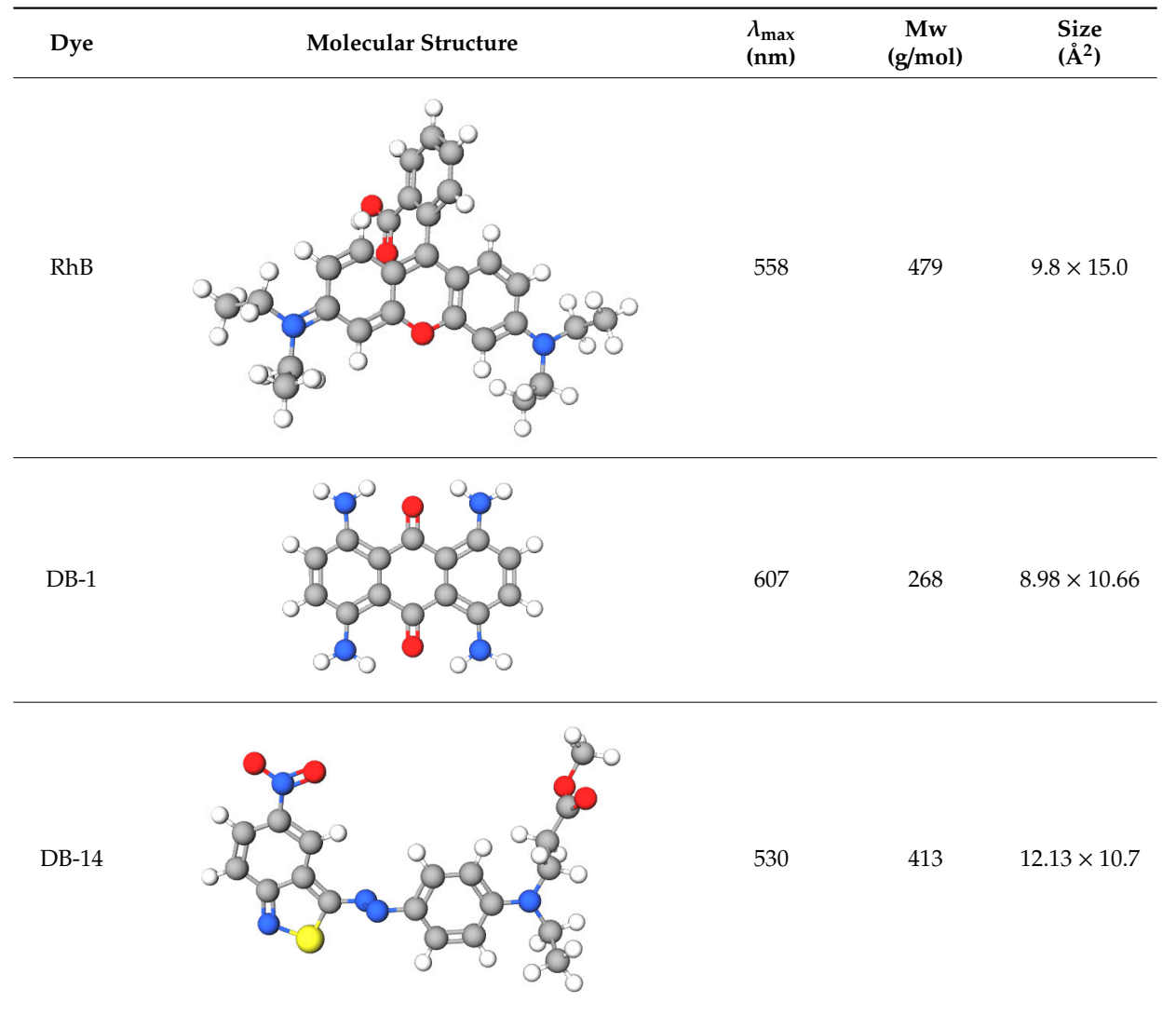

Note to ball stick: white: hydrogen; grey: carbon; red: oxygen; blue: nitrogen; yellow: sulphur.

\subsubsection{Adsorption to Various Dyes}

The robustness of the adsorbents in this study was investigated for various dyes. In general, the adsorption capacity increased at initial reaction and reached a steady condition after $100 \mathrm{~min}$. The steady condition occurred because of equilibrium surface interaction between adsorbents and pollutants. The adsorption behaviour of soluble dyes is more regular compared to insoluble dyes with porosity changes of ZSM-5. This may be due to adsorption competition between dye and solvent, thus limiting the dye penetration to adsorbent surface area. The dye adsorption in this study followed Langmuir isotherm, thus adsorbent surface area and functional group interaction of the dyes are influencing factors for the adsorption process, instead of solely directly proportion to dye sizes. The result indicated excellent adsorption performance of the ZSM- $5_{\text {deSil-deAl }}$ in decolorisation of CR (322.581 mg/g), RY (434.783 mg/g), MB (588.23 mg/g), RhB (625 mg/g), DB-1 (60.606 mg/g) and DB-14 (243.902 mg/g) which are comparable to well-known adsorbent [40] as presented in Table 6 . The excellent performance may be due its rich surface charge, porous structure and high specific surface area. The presence of micro, meso and macro-pore structure in ZSM-5 also eases adsorption to various dyes. 
Table 6. Comparison of existing study with several earlier reports.

\begin{tabular}{cccc}
\hline Adsorbents & Dye & Qm (mg/g) & Ref. \\
\hline Activated carbon/PEI & CR & 34.36 & {$[41]$} \\
\hline Starch/hydrogel & CR & 64.73 & {$[42]$} \\
\hline ZSM-5 deSil-deAl & CR & 322.581 & This study \\
\hline maleate-alumoxane & RY & 244 & {$[43]$} \\
\hline Surface modified AC & RY & 24.15 & {$[37]$} \\
\hline ZSM-5 $5_{\text {deSil-deAl }}$ & RY & 434.783 & This study \\
\hline Mesoporous birnessite & MB & 113 & {$[44]$} \\
\hline Biopolymer/ZSM-5 & MB & 548.16 & {$[33]$} \\
\hline MBM-BC & BC & 501 & {$[40]$} \\
\hline ZSM-5 deSil-deAl & MB & 588.235 & This study \\
\hline MoS2/MIL-101 hybrid (M-Fe ${ }_{3} /$ montmorillonite & RhB & 344.8 & {$[45]$} \\
\hline ZSM-5 $5_{\text {deSil-deAl }}$ & RhB & 625 & This study \\
\hline ZSM-5 $5_{\text {deSil-deAl }}$ & DB-1 & 60.606 & This study \\
\hline ZSM-5 deSil-deAl & DB-14 & 243.902 & This study \\
\hline
\end{tabular}

Qm: maximum adsorption capacity; AC: activated carbon; PEI: polyethylenimine; MBM-BC: Magnetic ball mill-biochar.

\subsection{Adsorption Kinetics}

Adsorption kinetics is a general approach to identify rate-controlling step and adsorption rate for certain reaction. There are three methods to investigate the adsorption process in this study namely pseudo first, pseudo second and intra-particle diffusion. The rate constant for the studied dyes of several adsorbents were elaborated using following Equations (6)-(9) [47].

$$
\begin{gathered}
\ln \left(\frac{Q_{e}}{Q_{t}}\right)=\ln Q e-k_{1} t \\
\frac{t}{Q_{t}}=\frac{1}{k_{2} Q_{e}^{2}}+\frac{t}{Q_{e}} \\
r=k_{2} Q_{e}^{2}
\end{gathered}
$$

where $Q_{e}(\mathrm{mg} / \mathrm{g})$ and $Q_{\mathrm{t}}(\mathrm{mg} / \mathrm{g})$ are adsorption at equilibrium and at time, respectively. Meanwhile, $k_{1}$ and $k_{2}$ are rate constant for pseudo first and second with $r$ as the reaction rate $(\mathrm{mg} /(\mathrm{g} \mathrm{min}))$.

The rate-determining step is calculated with Weber-Moris intraparticle model as follows

$$
Q_{t}=k_{P} t^{1 / 2}+C
$$

where $k_{P}$ and $C$ are rate constant of Weber-Moris and constant of boundary layer thickness, respectively.

Figure S4 summarises the kinetic parameters from pseudo-first and pseudo-second model. The adsorption process in this study occurs based on pseudo first model as its higher correlation coefficient $\left(R^{2}\right)$. Then, intra-particle diffusion could not be used as a definite model because of low $R^{2}(0.88-0.93)$ which showed that pore topologies is not the main influencing parameter. Thus, we suspected the interaction between dye molecules and adsorbent as the most crucial to be comprehend in this study. 


\subsection{Adsorption Mechanism}

The proposed adsorption mechanism of this study is presented in Figure 10. The strong attraction may occur between deprotonated silanol or aluminol groups and electron-rich site of dyes that led to fast adsorption studies in the first stage. At the same stage, medium attraction may also promote adsorption where delocalised $\pi$ electron in dye benzene ring is attracted to hydrogen atoms in the adsorbents. In addition, hydrogen bond may also contribute to the dye removal. Hydrogen bond is an intermolecular interaction between hydrogen atoms that exhibits low electronegativity to atoms with high electronegativity such as F, O and N. In this study, the adsorbent with many hydrogen atoms could interact with oxygen or nitrogen atoms in dye. Additionally, the hydrogen of the hydroxyl groups in dye could be attracted to oxygen in the adsorbents. The result from FTIR studies of fresh and spent adsorbent as presented in S5 proved the interaction in the functional groups as indicated by decreasing the intensity of spent adsorbents. Then, after a certain time, the adsorption experienced steady condition. This resulted in to equilibrium reaction between adsorbent and dye or the surface of adsorbents fully covered with dye, thus slowing the adsorption process. The similar mechanism was reported by Ouachtak et al. and validated molecular dynamics simulation [46].

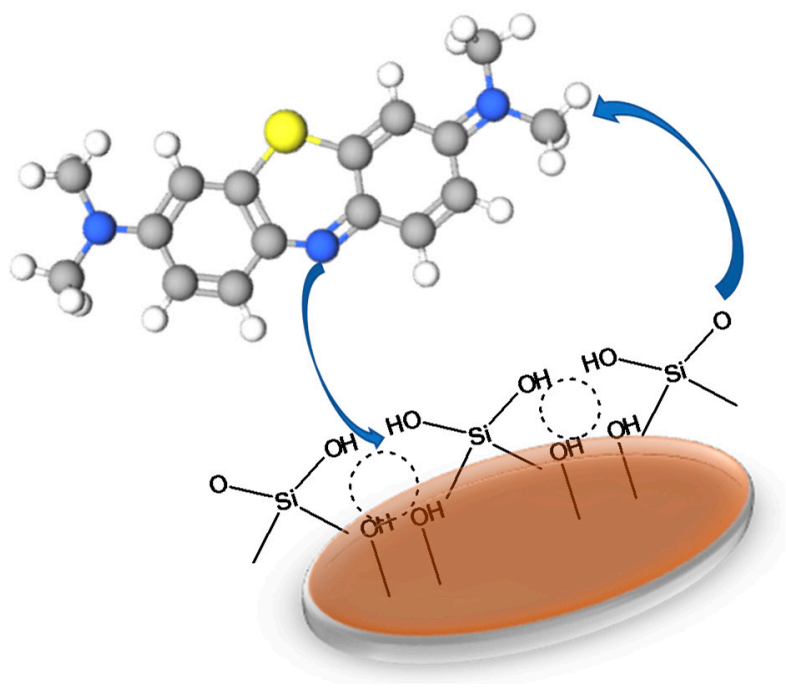

Figure 10. Proposed mechanism for dye adsorption on Hierarchical ZSM-5.

\section{Materials and Methods}

\subsection{Materials}

Commercial ZSM-5 was purchased from Jianxi-China with Si/Al ratio of 50 (H-ZSM-5) (Jianxi Tianhang Chemical Industry Co., Ltd.). Sodium hydroxide $(\mathrm{NaOH})$, acetic acid $\left(\mathrm{CH}_{3} \mathrm{COOH}\right)$, ammonium hydroxide $\left(\mathrm{NH}_{4} \mathrm{OH}\right)$ and hydrochloric acid $(\mathrm{HCl})$ were obtained from Merck Sdn Bhd, Selangor, Malaysia. Distilled water was used throughout the experiment and chemical reagents were used without further purification.

\subsection{Synthesis Hierarchical ZSM-5}

The powder of commercial ZSM-5 was dried at $110^{\circ} \mathrm{C}$ to remove excess of water prior to use. There are three routes to produce hierarchical ZSM- 5 in this study namely dealumination, desilication and combination of desilication-dealumination. In desilication, variable $\mathrm{NaOH}$ concentrations $(0.05$, $0.1,0.25,0.5$ and $1 \mathrm{M}$ ) were added to ZSM-5 with weight ratio of 30:1. This suspension was then stirred at $500 \mathrm{rpm}$ and $65^{\circ} \mathrm{C}$ with certain time intervals $(30,60,120 \mathrm{~min})$. Subsequently, the precipitate was dried at $105^{\circ} \mathrm{C}$ for $12 \mathrm{~h}$. The volatile compounds and water were removed at this stage, which produced Na-ZSM-5. Meanwhile, dealumination was conducted using various concentrations of 
$\mathrm{CH}_{3} \mathrm{COOH}(0.001,0.01$ and $0.05 \mathrm{M})$ with powder to solution ratio of 1:20. The suspension was heated at $60{ }^{\circ} \mathrm{C}$ for $3 \mathrm{~h}$, dried at $105^{\circ} \mathrm{C}$ and calcined at $550{ }^{\circ} \mathrm{C}$ to remove the impurities. Finally, the combination of alkaline and acidic treatment was conducted at their optimum concentration with the same experimental steps. For simplicity, the commercial ZSM-5, desilicated ZSM-5, dealuminated ZSM- 5 and combination of dealumination and desilication were denoted as ZSM- $5_{\text {comm }}$, ZSM- $5_{\text {deSil }}$, ZSM- $5_{\text {deAl }}$ and ZSM- $5_{\text {deSil-deAl }}$, respectively.

\subsection{Adsorbents Characterisation}

The nitrogen adsorption-desorption was conducted using Quantachrome Novatouch LX ${ }^{3}$ (Palm Beach County, Florida, FL, USA). Brunnauer-Emmet Teller (BET) was used to calculate surface area, while pore volume and pore size were estimated using Barret, Joyner and Halenda (BJH). The functional groups interaction before and after treatment were studied with Fourier-transformation infrared (FTIR) Shimadzu 8400 (Parkin Elmer, Frontier, Waltham, Massachussets, MA, USA) at wavelength scan of $500-4000 \mathrm{~cm}^{-1}$. Meanwhile, the crystallinity of zeolite was analysed by X-ray diffraction (XRD) JEOL JDX-3530 (PANalytical X'pert PRO, Amsterdam, Netherlands) in the range of 5-50 with scan rate of $0.04 \%$. Finally, the morphology of ZSM-5 adsorbents was elucidated with scanning electron microscopy (SEM) (JEOL, Tokyo, Japan) at $20 \mathrm{kV}$. The sample was coated with Pd/Au before the analysis to obtain clearer images.

\subsection{Batch Adsorption Studies}

The adsorption studies of the sample were carried out by using several soluble and insoluble dyes. The soluble dyes consist of Congo red (CR), Reactive Yellow 186 (RY-186), Rhodamine Blue (RhB) and Methylene Blue (MB) (Merck Sdn Bhd, Selangor, Malaysia). Meanwhile, Disperse Blue 1 (DB-1) and Disperse Blue 12 (DB-12) (Merck Sdn Bhd, Selangor, Malaysia) were utilised as model of insoluble dyes. The characteristics of the studied dyes are displayed in Table 5. For adsorption studies, $0.05 \mathrm{~g}$ of adsorbents were dissolved to $50 \mathrm{~mL}$ of dye with certain concentration $(60,100,150,200$ and $250 \mathrm{ppm})$ at $30^{\circ} \mathrm{C}$. The stirring rate was accelerated from $60 \mathrm{rpm}$ to $150 \mathrm{rpm}$ after complete mixing of adsorbent and dye with contact time in the range of $5-180 \mathrm{~min}$. The accuracy of the data was confirmed by repeating each experiment three times. Then, the adsorption capacity was calculated based on Equation (1).

$$
\text { Adsorption capacity }\left(q_{e}\right)=\left(C_{i}-C_{f}\right) \times V / M
$$

where $C_{i}$ and $C_{f}$ are initial and final concentration of dye (ppm), while $V$ and $M$ are volume of solution and mass of the adsorbent, respectively.

\section{Conclusions}

Hierarchical ZSM-5 was produced via top-down approach with fine-tuning properties. The optimum concentration for a sequence desilication and dealumination was determined from XRD crystallinity. After the treatment, the XRD peaks still maintained similar characteristic indicating non-destructive treatment with the existence of micro, meso and macro as identified with $\mathrm{N}_{2}$ adsorption-desorption. FTIR deconvolution studies revealed increasing intensity of terminal Si-OH and un-bridge $\mathrm{Si}-\mathrm{O}$ after the treatment which enlightened the process for unique pore formation. Then, various parameters such as effect of $\mathrm{pH}$, effect of initial dye concentration and effect of adsorbent type were elucidated with detail studies on isotherm, thermodynamic and kinetic. The adsorption process in this study occurs via Langmuir model with pseudo-first order kinetics. Finally, the adsorption mechanism is believed mostly as a result of electrostatic interaction, hydrogen bonding and van der Walls force.

Supplementary Materials: The following are available online at http://www.mdpi.com/2304-6740/8/9/52/s1, Figure S1: ZSM crystallinity; Figure S2: FTIR deconvolution at $1087 \mathrm{~cm}^{-1}$; Figure S3: $\mathrm{pH}$ of Point zero charge 
(pHpzc); Figure S4: Kinetic parameter of CR in several adsorbents with pseudo first and pseudo second; Figure S5: FTIR spectra of fresh and spend adsorbent.

Author Contributions: A.I.: conceptualization and data curation, A.M.: writing-original draft preparation, A.I.R.: investigation and methodology, D.H.: supervision, funding acquisition, M.S.: software and validation, H.N.: writing-review and editing, M.S.A.: visualization and formal analysis. All authors have read agreed to the published version of this manuscript.

Funding: This research was funded by Ministry of Education through Penelitian Terapan 110/SP2H/LT/DRPM/2019, 2889/L4/PP/2019, 40/LPPM-UP/KP-PT/III/2019 which also contribute to APC.

Acknowledgments: The authors acknowledge the collaboration between ITS-UTM.

Conflicts of Interest: The authors declare no conflict of interest.

\section{References}

1. Teow, Y.H.; Tajudin, S.A.; Ho, K.C.; Mohammad, A.W. Synthesis and characterization of graphene shell composite from oil palm frond juice for the treatment of dye-containing wastewater. J. Water Process Eng. 2020, 35, 101185. [CrossRef]

2. Holkar, C.R.; Jadhav, A.J.; Pinjari, D.V.; Mahamuni, N.M.; Pandit, A.B. A critical review on textile wastewater treatments: Possible approaches. J. Environ. Manag. 2016, 182, 351-366. [CrossRef] [PubMed]

3. Yagub, M.T.; Sen, T.K.; Afroze, S.; Ang, H.M. Dye and its removal from aqueous solution by adsorption: A review. Adv. Colloid Interface Sci. 2014, 209, 172-184. [CrossRef] [PubMed]

4. Rauf, M.A.; Salman Ashraf, S. Survey of recent trends in biochemically assisted degradation of dyes. Chem. Eng. J. 2012, 209, 520-530. [CrossRef]

5. Talaiekhozani, A.; Rezania, S. Application of photosynthetic bacteria for removal of heavy metals, macro-pollutants and dye from wastewater: A review. J. Water Process Eng. 2017, 19, 312-321. [CrossRef]

6. Ang, W.L.; Mohammad, A.W. State of the art and sustainability of natural coagulants in water and wastewater treatment. J. Clean. Prod. 2020, 262, 121267. [CrossRef]

7. Li, J.; Shi, C.; Zhang, H.; Zhang, X.; Wei, Y.; Jiang, K.; Zhang, B. Silicalite-1 zeolite membrane: Synthesis by seed method and application in organics removal. Chemosphere 2019, 218, 984-991. [CrossRef]

8. Melo, R.P.F.; Barros Neto, E.L.; Nunes, S.K.S.; Castro Dantas, T.N.; Dantas Neto, A.A. Removal of Reactive Blue 14 dye using micellar solubilization followed by ionic flocculation of surfactants. Sep. Purif. Technol. 2018, 191, 161-166. [CrossRef]

9. Fan, H.; Ma, Y.; Wan, J.; Wang, Y.; Li, Z.; Chen, Y. Adsorption properties and mechanisms of novel biomaterials from banyan aerial roots via simple modification for ciprofloxacin removal. Sci. Total Environ. 2020, 708, 134630. [CrossRef]

10. El-sayed, M.E.A. Nanoadsorbents for water and wastewater remediation. Sci. Total Environ. 2020, 739, 139903. [CrossRef]

11. Shamsudin, M.S.; Azha, S.F.; Shahadat, M.; Ismail, S. Cellulose/bentonite-zeolite composite adsorbent material coating for treatment of N-based antiseptic cationic dye from water. J. Water Process Eng. 2019, 29, 100764. [CrossRef]

12. Masudi, A.; Jusoh, N.W.C.; Muraza, O. Opportunities for less-explored zeolitic materials in the syngas-to-olefins pathway over nanoarchitectured catalysts: A mini review. Catal. Sci. Technol. 2020, 10, 1582-1596. [CrossRef]

13. Hartati; Trisunaryanti, W.; Mukti, R.R.; Kartika, I.A.; Dea Firda, P.B.; Sumbogo, S.D.; Prasetyoko, D.; Bahruji, H. Highly selective hierarchical ZSM-5 from kaolin for catalytic cracking of Calophyllum inophyllum oil to biofuel. J. Energy Inst. 2020, in press. [CrossRef]

14. Prasetyoko, D.; Ayunanda, N.; Fansuri, H.; Hartanto, D.; Ramli, Z. Phase Transformation of Rice Husk Ash in the Synthesis of ZSM-5 without Organic Template. J. Math. Fundam. Sci. 2014, 44, 250-262. [CrossRef]

15. Vegere, K.; Vitola, L.; Argalis, P.P.; Bajare, D.; Krauklis, A.E. Alkali-Activated Metakaolin as a Zeolite-Like Binder for the Production of Adsorbents. Inorganics 2019, 7, 141. [CrossRef]

16. Sokri, M.N.M.; Daiko, Y.; Mouline, Z.; Honda, S.; Iwamoto, Y. Formation of Micro and Mesoporous Amorphous Silica-Based Materials from Single Source Precursors. Inorganics 2016, 4, 5. [CrossRef]

17. Tao, H.; Li, C.; Ren, J.; Wang, Y.; Lu, G. Synthesis of mesoporous zeolite single crystals with cheap porogens. J. Solid State Chem. 2011, 184, 1820-1827. [CrossRef] 
18. Groen, J.C.; Bach, T.; Ziese, U.; Paulaime-van Donk, A.M.; de Jong, K.P.; Moulijn, J.A.; Pérez-Ramírez, J. Creation of Hollow Zeolite Architectures by Controlled Desilication of Al-Zoned ZSM-5 Crystals. J. Am. Chem. Soc. 2005, 127, 10792-10793. [CrossRef]

19. Jia, X.; Khan, W.; Wu, Z.; Choi, J.; Yip, A.C.K. Modern synthesis strategies for hierarchical zeolites: Bottom-up versus top-down strategies. Adv. Powder Technol. 2019, 30, 467-484. [CrossRef]

20. Pérez-Ramírez, J.; Abelló, S.; Bonilla, A.; Groen, J.C. Tailored Mesoporosity Development in Zeolite Crystals by Partial Detemplation and Desilication. Adv. Funct. Mater. 2009, 19, 164-172. [CrossRef]

21. Holm, M.S.; Hansen, M.K.; Christensen, C.H. “One-Pot” Ion-Exchange and Mesopore Formation During Desilication. Eur. J. Inorg. Chem. 2009, 2009, 1194-1198. [CrossRef]

22. Yue, Y.; Guo, X.; Liu, T.; Liu, H.; Wang, T.; Yuan, P.; Zhu, H.; Bai, Z.; Bao, X. Template free synthesis of hierarchical porous zeolite Beta with natural kaolin clay as alumina source. Microporous Mesoporous Mater. 2020, 293, 109772. [CrossRef]

23. Lv, Y.; Ye, C.; Zhang, J.; Guo, C. Rapid and efficient synthesis of highly crystalline SSZ-13 zeolite by applying high shear mixing in the aging process. Microporous Mesoporous Mater. 2020, 293, 109812. [CrossRef]

24. Hartanto, D.; Kurniawati, R.; Pambudi, A.B.; Utomo, W.P.; Leaw, W.L.; Nur, H. One-pot non-template synthesis of hierarchical ZSM-5 from kaolin source. Solid State Sci. 2019, 87, 150-154. [CrossRef]

25. Li, H.; Cheng, R.; Liu, Z.; Du, C. Waste control by waste: Fenton-like oxidation of phenol over Cu modified ZSM-5 from coal gangue. Sci. Total Environ. 2019, 683, 638-647. [CrossRef] [PubMed]

26. Sachse, A.; Grau-Atienza, A.; Jardim, E.O.; Linares, N.; Thommes, M.; García-Martínez, J. Development of Intracrystalline Mesoporosity in Zeolites through Surfactant-Templating. Cryst. Growth Des. 2017, 17, 4289-4305. [CrossRef]

27. Sivalingam, S.; Sen, S. Rapid ultrasound assisted hydrothermal synthesis of highly pure nanozeolite $X$ from fly ash for efficient treatment of industrial effluent. Chemosphere 2018, 210, 816-823. [CrossRef]

28. Akhtar, F.; Andersson, L.; Ogunwumi, S.; Hedin, N.; Bergström, L. Structuring adsorbents and catalysts by processing of porous powders. J. Eur. Ceram. Soc. 2014, 34, 1643-1666. [CrossRef]

29. Rostamizadeh, M.; Yaripour, F.; Hazrati, H. Ni-doped high silica HZSM-5 zeolite (Si/Al = 200) nanocatalyst for the selective production of olefins from methanol. J. Anal. Appl. Pyrolysis 2018, 132, 1-10. [CrossRef]

30. Abdulrasheed, A.A.; Jalil, A.A.; Hamid, M.Y.S.; Siang, T.J.; Fatah, N.A.A.; Izan, S.M.; Hassan, N.S. Dry reforming of methane to hydrogen-rich syngas over robust fibrous KCC-1 stabilized nickel catalyst with high activity and coke resistance. Int. J. Hydrog. Energy 2019. [CrossRef]

31. Wu, Y.; Su, M.; Chen, J.; Xu, Z.; Tang, J.; Chang, X.; Chen, D. Superior adsorption of methyl orange by h-MoS 2 microspheres: Isotherm, kinetics, and thermodynamic studies. Dye. Pigment. 2019, 170, 107591. [CrossRef]

32. Ma, J.; Jia, Y.; Jing, Y.; Yao, Y.; Sun, J. Kinetics and thermodynamics of methylene blue adsorption by cobalt-hectorite composite. Dyes Pigment. 2012, 93, 1441-1446. [CrossRef]

33. Brião, G.V.; Jahn, S.L.; Foletto, E.L.; Dotto, G.L. Highly efficient and reusable mesoporous zeolite synthetized from a biopolymer for cationic dyes adsorption. Colloids Surf. A Physicochem. Eng. Asp. 2018, 556, 43-50. [CrossRef]

34. Rizzi, V.; D’Agostino, F.; Fini, P.; Semeraro, P.; Cosma, P. An interesting environmental friendly cleanup: The excellent potential of olive pomace for disperse blue adsorption/desorption from wastewater. Dyes Pigment. 2017, 140, 480-490. [CrossRef]

35. Al-Degs, Y.S.; El-Barghouthi, M.I.; El-Sheikh, A.H.; Walker, G.M. Effect of solution pH, ionic strength, and temperature on adsorption behavior of reactive dyes on activated carbon. Dyes Pigment. 2008, 77, 16-23. [CrossRef]

36. Varghese, S.P.; Babu, A.T.; Babu, B.; Antony, R. $\gamma$-MnOOH nanorods: Efficient adsorbent for removal of methylene blue from aqueous solutions. J. Water Process Eng. 2017, 19, 1-7. [CrossRef]

37. Saravanan, A.; Karishma, S.; Jeevanantham, S.; Jeyasri, S.; Kiruthika, A.R.; Kumar, P.S.; Yaashikaa, P.R. Optimization and modeling of reactive yellow adsorption by surface modified Delonix regia seed: Study of nonlinear isotherm and kinetic parameters. Surf. Interfaces 2020, 20, 100520. [CrossRef]

38. Kulawong, S.; Chanlek, N.; Osakoo, N. Facile synthesis of hierarchical structure of NaY zeolite using silica from cogon grass for acid blue 185 removal from water. J. Environ. Chem. Eng. 2020, 8, 104114. [CrossRef]

39. Boscaro, P.; Cacciaguerra, T.; Cot, D.; Fajula, F.; Hulea, V.; Galarneau, A. C,N-doped $\mathrm{TiO}_{2}$ monoliths with hierarchical macro-/mesoporosity for water treatment under visible light. Microporous Mesoporous Mater. 2019, 280, 37-45. [CrossRef] 
40. Li, Y.; Zimmerman, A.R.; He, F.; Chen, J.; Han, L.; Chen, H.; Hu, X.; Gao, B. Solvent-free synthesis of magnetic biochar and activated carbon through ball-mill extrusion with $\mathrm{Fe}_{3} \mathrm{O}_{4}$ nanoparticles for enhancing adsorption of methylene blue. Sci. Total Environ. 2020, 722, 137972. [CrossRef]

41. Wong, S.; Ghafar, N.A.; Ngadi, N.; Razmi, F.A.; Inuwa, I.M.; Mat, R.; Amin, N.A.S. Effective removal of anionic textile dyes using adsorbent synthesized from coffee waste. Sci. Rep. 2020, 10, 2928. [CrossRef] [PubMed]

42. Sarmah, D.; Karak, N. Double network hydrophobic starch based amphoteric hydrogel as an effective adsorbent for both cationic and anionic dyes. Carbohydr. Polym. 2020, 242, 116320. [CrossRef] [PubMed]

43. Ghabaee, S.; Behin, J.; Ansari, M.; Rajabi, L. Synthesis and characterization maleate-alumoxane nanoparticles for removal of reactive yellow 84 dye from aqueous solution. Adv. Powder Technol. 2020, 31, 2061-2071. [CrossRef]

44. Guan, Y.; Wang, S.; Wang, X.; Sun, C.; Wang, Y.; Hu, L. Preparation of mesoporous Al-MCM-41 from natural palygorskite and its adsorption performance for hazardous aniline dye-basic fuchsin. Microporous Mesoporous Mater. 2018, 265, 266-274. [CrossRef]

45. Yang, C.; Cheng, J.; Chen, Y.; Hu, Y. Enhanced adsorption performance of $\mathrm{MoS}_{2}$ nanosheet-coated MIL-101 hybrids for the removal of aqueous rhodamine B. J. Colloid Interface Sci. 2017, 504, 39-47. [CrossRef] [PubMed]

46. Ouachtak, H.; El Haouti, R.; El Guerdaoui, A.; Haounati, R.; Amaterz, E.; Addi, A.A.; Akbal, F.; Taha, M.L. Experimental and molecular dynamics simulation study on the adsorption of Rhodamine $\mathrm{B}$ dye on magnetic montmorillonite composite $\gamma-\mathrm{Fe}_{2} \mathrm{O}_{3} @$ Mt. J. Mol. Liq. 2020, 309, 113142. [CrossRef]

47. Mittersteiner, M.; Schmitz, F.; Barcellos, I.O. Reuse of dye-colored water post-treated with industrial waste: Its adsorption kinetics and evaluation of method efficiency in cotton fabric dyeing. J. Water Process Eng. 2017, 17, 181-187. [CrossRef]

(C) 2020 by the authors. Licensee MDPI, Basel, Switzerland. This article is an open access article distributed under the terms and conditions of the Creative Commons Attribution (CC BY) license (http://creativecommons.org/licenses/by/4.0/). 